\title{
Hubungan Antara Usia dan Tingkat Pengetahuan Dengan Penanganan Dismenore Pada Remaja Putri Di SMK Widya Utama Indramayu Tahun 2019
}

\author{
Relationship Between Age and Knowledge With Handling of Dysmenorrhea in Young Women \\ in SMK Widya Utama Indramayu 2019
}

\begin{tabular}{cc}
\hline & Tutin Marlia \\
\hline & Akper Saifuddin Zuhri Indramayu \\
Email: marliatutin@ yahoo.com
\end{tabular}

\begin{abstract}
Dismenorea merupakan nyeri yang dirasakan ketika haid. Dismenore biasanya baru timbul 2 atau 3 tahun sesudah menarche atau pertama kali menstruasi. Dismenore ada yang ringan dan ada yang samar - samar, ada pula yang berat bahkan beberapa wanita telah pingsan dan ada yang harus ke dokter karena nyeri yang dialaminya mengganggu aktivitasnya. Ternyata hampir 30 $\%$ wanita yang mengeluhkan dismenore adalah anak gadis dari ibu yang dulunya dismenore, serta sebanyak $7 \%$ saudara wanita yang mengalami dismenore juga mengeluhkan hal yang sama, meskipun ibu mereka dulunya tidak mengeluhkan dismenore. Untuk menangani nyeri haid tersebut ada dua hal yang dapat dilakukan yaitu secara medis dan non-medis. Nyeri saat haid tidak boleh dibiarkan begitu saja tanpa adanya upaya penanganan, karena mungkin saja gejala endometriosis bisa mempersulit wanita untuk hamil. Wanita Indonesia yang mengalami dismenore lebih banyak mengatasinya dengan mengkonsumsi obatobatan penghilang rasa nyeri yang beredar dipasaran. Sebagian masyarakat mempunyai anggapan yang salah bahwa nyeri ini dapat hilang dengan sendirinya apabila wanita yang bersangkutan menikah, sehingga mereka membiarkan gangguan tersebut. Penelitian ini bertujuan untuk mengetahui hubungan antara usia dan pengetahuan dengan penanganan dismenore. Metode penelitian ini dengan menggunakan metode korelasi menggunakan sampel secara acak sistematis terhadap 60 siswi. Hasil penelitian Tidak terdapat hubungan antara usia responden dengan cara penanganan dismenore dengan nilai p 0.429 lebih tinggi dibandingkan nilai $\alpha$ 0.05. Terdapat hubungan yang signifikan antara tingkat pengetahuan dengan cara penanganan dismenore dengan nilai p 0.012.Berdasarkan hasil penelitian tersebut diharapkan Remaja putri diharapkan dapat memilih cara penangan untuk menurunkan nyeri saat menstruasi (dismenore) dengan cara yang aman sehingga tidak memberikan efek yang membahayakan bagi tubuh.
\end{abstract}

Kata Kunci: Dismenore. pengetahuan. Usia. Remaja

\begin{abstract}
Dysmenorrhea is a pain perceived during the menstruation. Dysmenorrhea usually occurs in 2 or 3 years after menarche or the first menstruation. Some dysmenorrhea is mild and some are vague, some are severe even some women have passed out and some have to see a doctor because the pain they experienced disturb their activities. It turns out that almost $30 \%$ of women who complain of dysmenorrhea are daughters of mothers who used to have dysmenorrhea, and as many as $7 \%$ of sisters who experience dysmenorrhea also complain of the same thing, even though their mothers did not complain of dysmenorrhea. To handle this pain there are two things that can be done medically and non-medically. Pain during the menstruation cannot be ignored without the treatment, because it may be the symptoms of endometriosis that can make women difficult to get pregnancy. Indonesian women who got dysmenorrhea prefer to overcome it by taking painkillers released in the market. Most people have the wrong assumption that this pain can be eliminated itself if that women had married, therefore they ignored that problems. This study aims to know the relationship between age and knowledge with dysmenorrhea treatments. This research method used correlation method by using random sampling of 60 students. The results of the study showed that there was no relationship between the age of respondents with the way in handling dysmenorrhea with $p$ value of 0.429 higher than the $a$ value of 0.05 . There is a significant relationship between knowledge and how to handle dysmenorrhea with $p$ value of 0.012 . Based on the results of the study, the young women are expected to choose the proper treatments to reduce the pain during the menstruation (dysmenorrhea) in a safe way so that it does not give harmful effect on the body.
\end{abstract}

Keywords: Dysmenorrhea, Knowledge, Teenager Age

DOI : https://doi.org/10.31943/afiasi.v5i1.92 


\section{Pendahuluan}

Masa remaja merupakan masa transisi atau disebut juga masa peralihan dari masa anakanak menuju masa dewasa. Dimasa ini banyak terjadi perubahan pada diri remaja, baik dari aspek fisik, psikologis, social, intelektal maupun termasuk didalamnya pertumbuhan organ-organ reproduksi (organ seksual) untuk mencapai kematangan yang ditunjukan dengan kemampuan melaksanakan fungsi reproduksi. Perubahan yang terjadi pada pertumbuhan tersebut diikuti munculnya tanda-tanda seks primer maupun seks sekunder.

Salah satu ciri keberfungsian dari organ-organ repruduksi salah satunya adalah menstruasi yang akan dialami oleh remaja putri. Menstruasi adalah perdarahan vagina secara berkala akibat terlepasnya lapisan endometrium uterus. Usia normal bagi seorang wanita mendapat menstruasi untuk pertama kalinya pada usia 12 atau 13 tahun. Tetapi ada juga yang mengalaminya lebih awal, yaitu pada usia 8 tahun atau lebih lambat yaitu usia 18 tahun. Menstruasi akan berhenti dengan sendirinya pada saat wanita sudah berusia 40-50 tahun, yang dikenal dengan istilah menopause. ${ }^{1}$

Setiap wanita dalam menghadapi proses menstruasi memiliki pengalaman yang berbedabeda, ada yang tanpa keluhan, ada pula yang mengalami keluhan yang membuat wanita tersebut menjadi tidak nyaman, salah satunya adalah keluhan nyeri menstruasi atau dismenore. Dismenore biasanya baru timbul 2 atau 3 tahun sesudah menarche atau pertama kali menstruasi. Dismenore ada yang ringan dan ada yang samar - samar, ada pula yang berat bahkan beberapa wanita telah pingsan dan ada yang harus ke dokter karena nyeri yang dialaminya mengganggu aktivitasnya. Ternyata hampir $30 \%$ wanita yang mengeluhkan dismenore adalah anak gadis dari ibu yang dulunya dismenore, serta sebanyak 7\% saudara wanita yang mengalami dismenore juga mengeluhkan hal yang sama, meskipun ibu mereka dulunya tidak mengeluhkan dismenore. ${ }^{2}$

Dismenore merupakan nyeri perut bagian bawah yang terkadang rasa nyeri tersebut meluas hingga ke pinggang, punggung bagian bawah dan paha ${ }^{(2)}$. Dismenore merupakan nyeri yang dirasakan ketika haid, untuk menangani nyeri haid tersebut ada dua hal yang dapat dilakukan yaitu secara medis dan non-medis. ${ }^{3}$ Nyeri saat haid tidak boleh dibiarkan begitu saja tanpa adanya upaya penanganan, karena mungkin saja gejala endometriosis bisa mempersulit wanita untuk hamil. Wanita Indonesia yang mengalami dismenore lebih banyak mengatasinya dengan mengkonsumsi obat-obatan penghilang rasa nyeri yang beredar dipasaran. Sebagian masyarakat mempunyai anggapan yang salah bahwa nyeri ini dapat hilang dengan sendirinya apabila wanita yang bersangkutan menikah, sehingga mereka membiarkan gangguan tersebut.

Masalah dismenore merupakan salah satu masalah ginekologi yang paling umum dialami wanita dari berbagai tingkat usia. Angka kejadian dismenore di dunia sangat besar. Rata-rata lebih dari $50 \%$ perempuan di setiap dunia mengalaminya. Dari hasil penelitian di Amerika Serikat persentase kejadian dismenore sekitar 60\%, Swedia 72\% dan di Indonesia 55\%. Penelitian di Amerika Serikat menyebutkan bahwa dismenore dialami oleh 30-50\% wanita usia reproduksi dan 10-15\% diantaranya kehilangan kesempatan kerja, mengganggu kegiatan belajar di sekolah dan kehidupan keluarga. ${ }^{4}$

Dismenore cenderung terjadi lebih sering dan lebih hebat, pada gadis remaja yang mengalami kegelisahan, ketegangan dan kecemasan. Dalam beberapa penelitian juga disebutkan bahwa dismenore yang timbul pada remaja putri merupakan dampak dari kurang pengetahuannya mereka tentang dismenore. Mereka tidak siap dalam menghadapi menstruasi dan segala hal yang akan dialami oleh remaja putri. Akhirnya kecemasan melanda mereka dan 
mengakibatkan penurunan terhadap ambang nyeri yang pada akhirnya membuat nyeri haid menjadi lebih berat.

Karena penderita terbanyak adalah pada wanita usia produktif, akibatnya dismenorea juga menyebabkan ketidakhadiran saat bekerja dan sekolah, sebanyak 13-51\% wanita telah absen sekali dan $5-14 \%$ berulang kali absen. ${ }^{5}$ Penelitian di Amerika Serikat menyebutkan bahwa dismenore dialami oleh 30-50\% wanita usia reproduksi dan 10-15\% diantaranya kehilangan kesempatan kerja, mengganggu kegiatan belajar di sekolah dan kehidupan keluarga. ${ }^{6}$

Tingginya angka prevalensi dan morbiditas dari dismenorea primer kurang mendapat perhatian dari dunia medis, dikarenakan banyak wanita yang dikondisikan untuk menerima rasa sakit itu sebagai sesuatu yang normal, bersifat psikis walaupun hal tersebut menghambat aktivitas mereka sehari-hari dan menurunkan kualitas hidup wanita. ${ }^{7}$

Penelitian sebelumnya menunjukan bahwa dari 133 responden didapatkan data sebanyak 44\% memiliki pengetahuan cukup tentang dismenore dan sebanyak 45,1\% memiliki perilaku tidak baik dalam mengatasi dismenore. ${ }^{8}$ Pengetahuan remaja putri mengenai dismenoremasih belum cukup baik sehingga banyak remaja putri yang tidak mengetahui bagaimana cara penanganan dismenorea yang benar. Berdasarkan penelitian yang dilakukan di Demak diketahui $78,3 \%$ siswi memiliki pengetahuan yang kurang tentang dismenore, hanya $4,3 \%$ siswi yang memiliki pengetahauan yang baik mengenai dismenore. ${ }^{9}$

Kurangnya tingkat pengetahuan mengenai kesehatan reproduksi dapat di karenakan kurangnya sumber informasi. Pengetahuan mengenai kesehatan reproduksi yang diberikan di sekolah hanya didapatkan melalui mata pelajaran biologi. Materi yang diajarkan hanya mengajarkan anatomi hewan, tumbuhan, dan susunan anatomi organ reproduksi beserta manfaatnya, tidak membahas permasalahan yang menyertai sistem reproduksi ${ }^{(9)}$. Hasil penelitian ini diharapkan dapat menambah wawasan pembaca tentang cara peanganan dismenor yang aman serta mudah untuk dilakukan.

\section{Metode Penelitian}

Jenis penelitian yang digunakan dalam penelitian ini adalah penelitian kuantitatif dengan menggunakan metode studi korelasi. ${ }^{10}$ Populasi dalam penelitian ini adalah seluruh siswi SMK Widya Utama sejumlah 159 siswi. Teknik pengambilan sampel dalam penelitian ini menggunakan sampel secara acak sistematis dan hasil hitung menghasilkan 60 responden sebagai sampel penelitian ini. Teknik pengumpulan data menggunakan instrumen jenis kuisioner. Analisa data menggunakan univariat, bivariat dengan menggunakan uji chi square.

\section{Hasil}

Berikut ini adalah analisis hasil penelitian yang ditampilkan dalam bentuk tabel yang menggambarkan distribusi frekuensi dari masing-masing variabel, hubungan antar variabel dan variabel yang diteliti. 
a. Analisis Univariat

\section{Distribusi Frekuensi Usia Responden}

Tabel 1. Distribusi Frekuensi Usia Responden di SMK Widya Utama Indramayu Tahun 2019

\begin{tabular}{lcc}
\hline Usia Responden & Frekuensi (n) & Presentase \% \\
\hline$\leq 17$ tahun & 50 & 82.0 \\
$>17$ tahun & 11 & 18.0 \\
Total & 61 & 100.0 \\
\hline
\end{tabular}

Berdasarkan tabel 1 dapat dijelaskan bahwa responden dengan usia kurang dari sama dengan 17 tahun lebih banyak (82\%) dibandingkan dengan responden yang usianya lebih dari 17 tahun $(18 \%)$.

2.Distribusi Frekuensi Pengetahuan Responden

Tabel 2. Distribusi Frekuensi Pengetahuan Responden Tentang Dismenore di SMK Widya Utama Indramayu Tahun 2019

\begin{tabular}{lcc}
\hline Pengetahuan & Frekuensi (n) & Presentase \% \\
\hline Baik & 48 & 78.7 \\
Kurang & 13 & 21.3 \\
Total & 61 & 100.0 \\
\hline
\end{tabular}

Berdasarkan tabel 2 dapat dijelaskan bahwa tingkat pengetahuan remaja putri memiliki jumlah terbanyak pada kategori pengetahuan baik (78.7\%) dibandingkan dengan remaja putri yang berpengetahuan kurang $(21.3 \%)$.

\section{Distribusi Frekuensi Cara Penanganan Dismenore}

Tabel 3. Distribusi Frekuensi Cara Penanganan Dismenore di SMK Widya Utama Indramayu Tahun 2019

\begin{tabular}{lcc}
\hline \multicolumn{1}{c}{ Pengetahuan } & Frekuensi (n) & Presentase \% \\
\hline Tanpa obat & 44 & 72.1 \\
Dengan obat & 17 & 27.9 \\
Total & 61 & 100.0 \\
\hline
\end{tabular}

Berdasarkan tabel 3 dapat dijelaskan bahwa responden yang mengalami dismenore sebagian besar menangani masalah tersebut dengan tanpa minum obat yaitu sejumlah $(72.1 \%)$ sedangkan responden yang menangani dismenore dengan minum obat sebanyak $27.9 \%$. 


\section{b. Analisis Bivariat}

\section{Hubungan Usia Responden Dengan Penanganan Dismenore}

Tabel 4. Hubungan Usia Responden Dengan Penanganan Dismenore Di SMK Widya Utama Indramayu Tahun 2019

\begin{tabular}{|c|c|c|c|c|c|c|c|}
\hline \multirow[t]{3}{*}{ Usia } & \multicolumn{4}{|c|}{ Penanganan Dismenore } & \multicolumn{2}{|c|}{ Total } & \multirow[t]{3}{*}{ Nilai $\mathrm{p}$} \\
\hline & \multicolumn{2}{|c|}{ Tanpa Obat } & \multicolumn{2}{|c|}{ Dengan Obat } & \multirow[t]{2}{*}{$\mathrm{N}$} & \multirow[t]{2}{*}{$\%$} & \\
\hline & $\mathrm{N}$ & $\%$ & $\mathrm{~N}$ & $\%$ & & & \\
\hline$\leq 17$ tahun & 35 & 70 & 15 & 30 & 50 & 100 & 0.429 \\
\hline 17 tahun & 9 & 81.8 & 2 & 18.2 & 11 & 100 & \\
\hline
\end{tabular}

Berdasarkan tabel 4 dapat dijelaskan bahwa responden yang berusia kurang dari sama dengan 17 tahun lebih banyak tidak mengkonsumsi obat pada saat mengalami dismenore sebanyak 70\%, begitu juga dengan responden yang berusia lebih dari 17 tahun lebih banyak menangani dismenorenya dengan tanpa minum obat yaitu sebanyak 81.8\%. Tidak terdapat hubungan antara usia responden dengan cara penanganan dismenore dengan nilai $p \quad 0.429$ lebih tinggi dibandingkan nilai $\alpha 0.05$.

2. Hubungan Tingkat Pengetahuan Responden Tentang Dismenore Dengan Cara Penanganan Dismenora

Tabel 5. Hubungan Tingkat Pengetahuan Responden Tentang Dismenore Dengan Cara Penanganan Dismenora di SMK Widya Utama Indramayu Tahun 2019

\begin{tabular}{lccccccc}
\hline \multirow{2}{*}{ Pengetahuan } & \multicolumn{3}{c}{ Penanganan Dismenore } & \multicolumn{2}{c}{ Total } & \multirow{2}{*}{ Nilai p } \\
\cline { 2 - 6 } & \multicolumn{2}{c}{ Tanpa Obat } & \multicolumn{2}{c}{ Dengan Obat } & $\mathrm{N}$ & $\%$ & \\
\cline { 2 - 6 } & $\mathrm{N}$ & $\%$ & $\mathrm{~N}$ & $\%$ & & & \\
\hline Baik & 31 & 64.5 & 17 & 35.5 & 48 & 100 & \multirow{2}{*}{0.012} \\
\hline Kurang & 13 & 100 & 0 & 0 & 13 & 100 & \\
\hline
\end{tabular}

Berdasarkan tabel 5 dapat dijelaskan bahwa untuk responden yang berpengetahuan baik sebagian besar memilih tanpa obat untuk menangani dismenorenya yaitu sebanyak $64.5 \%$, begitu juga pada responden yang memiliki pengetahuan kurang, 100\% responden memilih tanpa obat dalam menangani dismenorenya. Terdapat hubungan yang signifikan antara tingkat pengetahuan dengan cara penanganan dismenore dengan nilai p 0.012 .

\section{Pembahasan}

\section{Hubungan Usia Dengan Penanganan Dismenore}

Periode masa remaja terbagi menjadi tiga bagian yaitu remaja awal, remaja menengah dan remaja akhir. Pengambilan sampel pada penelitian ini mengelompokan usia remaja menjadi 2 bagian yaitu remaja yang berusia kurang dari 17 tahun dimana mereka masuk pada kelompok remaja usia menengah, sedangkan remaja yang berusia lebih dari 17 tahun masuk dalam kelompok usia remaja akhir. Remaja tahap awal (10-14 tahun) hanya memiliki pemahaman yang samar tentang dirinya. Mereka tidak mampu mengaitkan perilaku mereka dengan konsekuensi perilaku tersebut. Remaja tahap menengah (15-16 tahun) bergumul dengan perasaan tergantung versus mandiri karena kawan-kawan sebaya menggantikan 
kedudukan orang tua. Mereka memiliki kecenderungan lebih besar untuk menunjukan variasi emosi mereka yang luas. Remaja tahap awal dan menengah belajar dan menerima informasi tetapi tidak mampu menerapkan informasi tersebut dalam kehidupan mereka. Remaja tahap akhir (17-21 tahun) memahami dirinya dengan baik dan dapat mengaitkan dengan jelas informasi yang abstrak ke dalam hidupnya. ${ }^{11}$

Berdasarkan hasil penelitian di dapatkan data kelompok usia kurang dari 17 tahun jumlahnya lebih mendominasi (82\%) dibanding kelompok usia yang lebih dari 17 tahun (18\%). Dalam penelitian ini tidak terdapat hubungan antara usia dengan pengambilan keputusan untuk menangani dismonere apakah menggunakan obat atau tanpa obat dengan nilai $\mathrm{p}$ 0.429. Responden yang berusia kurang dari 17 tahun maupun yang lebih dari 17 tahun lebih banyak memilih menangani dismenorenya dengan tanpa obat dibandingkan dengan obat. Hal ini dimungkinkan karena anak usia SMK merupakan periode remaja tahap akhir dimana tingkat kematangan dalam proses berfikir dan pengambilan keputusan lebih terarah dan matang.

Remaja dalam penelitian ini didominasi oleh kelompok remaja pada tahap menengah yang artinya mereka lebih banyak bergaul dan berkumpul dengan kelompok teman sebayanya. Untuk hal-hal yang sifatnya pribadi seperti keluhan menstruasi biasanya mereka lebih terbuka bercerita dengan teman sebayanya dibandingkan kepada orang tuanya karena enggan dan rasa malu jika bercerita kepada orang tua atau orang yang lebih dewasa.

Remaja putri mengalami menarche atau menstruasi pertama kali yang bisa terjadi dalam rentang usia 10 - 16 tahun, oleh karena itu tentunya responden telah mempunyai pengalaman didalam penanganan dismenorea dikaikan dengan waktu pertama kali responden mengalami menarche. Dengan adanya pengalaman mengalami dismenorea, maka responden dapat melakukan upaya penurunkan intensitas nyeri pada saat dismenore. ${ }^{3}$.

\section{Hubungan Pengetahuan Dengan Penanganan Dismenore}

Dalam penelitian ini peneliti mengelompokan tingkat pengetahuan kedalam 2 kelompok, yaitu tingkat pengetahuan baik dan tingkat pengetahuan kurang. Berdasarkan hasil penelitian disapatkan data responden yang mempunyai timgkat pengetahuan baik sebanyak $78.7 \%$ dan responden yang memiliki tingkat pengetahuan kurang sebanyak $21.3 \%$. Responden yang berpengetahuan baik sebagian besar memilih tanpa obat untuk menangani dismenorenya yaitu sebanyak $64.5 \%$, begitu juga pada responden yang memiliki pengetahuan kurang, $100 \%$ responden memilih tanpa obat dalam menangani dismenorenya. Terdapat hubungan yang signifikan antara tingkat pengetahuan dengan cara penanganan dismenore dengan nilai $\mathrm{p} 0.012$.

Hasil penelitian ini sejalan dengan penelitian yang dilakukan oleh Purwani, dkk bahwa ada hubungan antara tingkat pengetahuan dan sikap dengan penanganan dismenore, ${ }^{12}$ begitu juga penelitian yang dilakukan oleh Kusmiyati bahwa responden lebih banyak melakukan penangan dismenore dengan cara non farmakologi atau tanpa menggunakan obat. $^{13}$

SMK Widya Utama adalah salah satu SMK kesehatan di bidang Keperawatan dan Farmasi, jadi tidak menutup kemungkinan tigginya tingkat pengetahuan responden dipengaruhi oleh materi-materi yang diterima oleh siswa saat proses pembelajaran yang tidak lepas dari materi kesehatan seperti anatomi fisiologi tubuh manusia yang didalamnya 
terdapat materi anatomi fisiologi sistem reproduksi, materi kesehatan reproduksi dan ilmu farmakologi.

Selain itu responden juga menerima banyak informasi mengenai pengetahuan tentang dismenore dari media khususnya media internet. Sesuai dengan teori menurut Notoatmodjo, bahwa pengetahuan merupakan hasil dari tahu, dan ini terjadi setelah orang melakukan pengindraan terhadap suatu objek tertentu. Pengindraan terjadi melalui pancaindra manusia, yakni indra penglihatan, pendengaran, penciuman, rasa, dan raba.

Seseorang yang mempunyai sumber informasi lebih banyak akan mempunyai pengetahuan yang lebih luas. Informasi yang diperoleh dari beberapa sumber akan meningkatkan tingkat pengetahuan seseorang. Bila seseorang banyak memperoleh informasi maka ia cenderung memiliki pengetahuan yang lebih luas. ${ }^{4}$

Dalam penelitian ini peneliti mengelompokan cara penanganan dismenore menjadi 2 bagian yaitu dengan obat dan tanpa obat. Berdasarkan hasil penelitian didapatkan data bahwa responden lebih banyak menangani dismenorenya dengan tanpa obat yaitu sebanyak $72.1 \%$ dibandingkan responden yang menangani dismenore dengan obat 27.9\%. Hal ini mungkin dipengaruhi karena jenis pendidikan yang ditempuh oleh responden yaitu dalam bidang keperawatan dan farmasi.

Paparan informasi dari mater-materi pembelajaran yang dipelajari oleh siswi tersebut dalam setiap harinya dimana mereka mempelajari tentang ilmu farmakologi (obat-obatan) sehingga mayoritas mereka mengetahui jika sering mengkonsumsi obat-obatan maka hal ini akan membahayakan bagi tubuhnya. Apalagi menstruasi merupakan suatu siklus yang terjadi pada wanita sepanjang daur hidupnya sampai mereka mengalami menopouse.

Secara hormonal terjadinya dismenore (nyeri haid) disebabkan oleh peningkatan kadar prostaglandin di dalam darah yang merangsang peningkatan kontraksi dan disritmik uterus, sehingga terjadi penurunan aliran darah dan oksigen ke uterus yang mengakibatkan iskemia. Munculnya respon dari reseptor disebabkan adanya stimulus yang membahayakan dan memulai transmisi neural dengan melepaskan substansi yang menghasilkan nyeri. Lebih lanjut dijelaskan, sensasi nyeri terjadi ketika merasakan nyeri, individu bereaksi terhadap nyeri dengan cara yang berbeda. ${ }^{15}$

Dismenore yang terjadi pada remaja disebabkan oleh proses menstruasi itu sendiri yang merangsang otot-otot rahim untuk berkontraksi. Kontraksi otot rahim tersebut membuat aliran darah menjadi berkurang yang berakibat meningkatnya aktivitas rahim untuk memenuhi kebutuhannya akan aliran darah yang lancar, otot yang kekurangan darah tadi akan merangsang ujung saraf, sehingga terasa nyeri. ${ }^{7}$

Cara alamiah atau non obat merupakan cara yang lebih baik menurut sebagian besar responden. Adapun cara yang mereka lakukan adalah relaksasi dengan cara tarik nafas dalam, mengolesi daerah perut dengan minyak kayu putih, tehnik distraksi dengan cara mengalihkan perhatian seperti menonton TV, pijatan daerah nyeri serta kompres hangat daerah abdomen.

Pijatan yang dilakukan didaerah nyeri akan membantu memperlancar sirkulasi darah yang terganggu dan meningkatkan kenyamanan, sehingga mengurangi rangsangan nyeri. Pijatan juga dapat mengurangi ketegangan otot dan stress tubuh secara keseluruhan, dengan tujuan utama agar tubuh dan pikiran rileks. Relaksasi nafas dalam juga banyak dipilih mahasiswa, relaksasi juga menurunkan nyeri dengan merelaksasikan ketegangan otot yang mendukung rasa nyeri. 
Pemijatan akan meningkatkan aliran darah, yang pada gilirannya akan memeras pembuluh kapiler dan kelenjar getah bening serta membuang racun dari tubuh. Tubuh akan memberikan respon untuk meningkatkan aliran darah dengan memproduksi lebih banyak sel darah merah yang membawa oksigen ke otot, memberikan rasa nyaman dan mendorong pikiran untuk memproduksi endorphin yang merupakan penghilang rasa sakit yang alami bagi tubuh. ${ }^{16}$

Kompres hangat akan memberikan efek vasodilatasi pembuluh darah sehingga dapat meningkatkan aliran darah ke bagian tubuh yang mengalami cidera dan menurunkan ketegangan otot, sehingga meningkatkan relaksasi otot dan mengurangi nyeri. Seperti pendapat Potter et al stimulasi panas dapat menimbulkan respon fisiologis yang berbeda, efek terapeutik dari pemberian kompres diantaranya adalah permeabilitas kapiler meningkat, vasodilatasi (meningkatkan aliran darah), viskositas darah menurun, ketegangan otot menurun dan metabolism jaringan meningkat. ${ }^{15}$

Cara menangani dismenore dengan menggunakan obat merupakan cara yang praktis dan cepat menurut sebagain responden. Sesuai dengan teori yang menyebutkan bahwa bagi kebanyakan wanita, pil penghilang rasa sakit yang dijual bebas seperti aspirin dan ibuprofen sangat efektif untuk menghentikan kram. Obat ini menghalangi pengaruh proses kimia dalam tubuh yang disebut prostaglandin, yang banyak bertanggung jawab menyebabkan rasa sakit. Wanita bisa mulai mengkonsumsi obat ini ketika kram menyerang, tetapi akan lebih efektif jika anda meminumnya satu atau dua hari sebelumnya dan dilanjutkan sampai kramnya hilang. ${ }^{17}$

Pemilihan upaya penanganan dismenore (nyeri haid) lebih disebabkan kebiasaan masing-masing individu dan tingkat kenyamanan yang mereka rasakan. Seperti pendapat Kusmiyati yang menyatakan bahwa nyeri merupakan mekanisme fisiologis yang bertujuan untuk melindungi diri. ${ }^{13}$ Apabila seseorang merasakan nyeri, maka perilakunya akan berubah. Tamsuri menyebutkan reseptor nyeri (nosiseptor) adalah organ tubuh yang berfungsi untuk menerima rangsang nyeri, Organ tubuh yang berperan sebagai reseptor nyeri adalah ujung saraf bebas dalam kulit yang berespons hanya terhadap stimulus kuat yang secara potensial merusak. Lebih lanjut dijelaskan berdasarkan letaknya, nosiseptor dikelompokkan dalam beberapa bagian tubuh yaitu kulit, somatic dalam dan daerah visceral., karena letaknya yang berbeda-beda, maka nyeri yang timbul juga memiliki sensasi yang berbeda, Asmadi menambahkan, nyeri merupakan sensasi yang rumit, unik, universal dan bersifat individual, karena respon individu terhadap sensasi nyeri beragam dan tidak disamakan satu dengan lainnya. ${ }^{19}$

Apapun cara yang dipilih oleh responden untuk menurunkan atau mengatasi dismenore baik itu menggunakan obat maupun tanpa obat pada dasarnya memiliki tujuan yang sama yaitu untuk meringankan rasa nyeri dan meningkatkan kenyamanan saat menstruasi.

\section{Kesimpulan}

1. Responden dengan usia kurang dari sama dengan 17 tahun lebih banyak (82\%) dibandingkan dengan responden yang usianya lebih dari 17 tahun (18\%).

2. Tingkat pengetahuan remaja putri memiliki jumlah terbanyak pada kategori pengetahuan baik (78.7\%) dibandingkan dengan remaja putri yang berpengetahuan kurang $(21.3 \%)$. 
3. Responden yang mengalami dismenore sebagian besar menangani masalah tersebut dengan tanpa minum obat yaitu sejumlah $(72.1 \%)$ sedangkan responden yang menangani dismenore dengan minum obat sebanyak $27.9 \%$.

4. Tidak terdapat hubungan antara usia responden dengan cara penanganan dismenore dengan nilai p 0.429 lebih tinggi dibandingkan nilai $\alpha 0.05$.

5. Terdapat hubungan yang signifikan antara tingkat pengetahuan dengan cara penanganan dismenore dengan nilai $\mathrm{p} 0.012$.

\section{Saran}

\section{Bagi Remaja Putri}

Remaja putri diharapkan dapat memilih cara penangan untuk menurunkan nyeri saat menstruasi (dismenore) dengan cara yang aman sehingga tidak memberikan efek yang membahayakan bagi tubuh, cara yang paling aman adalah dengan tanpa minum obat, adapun cara yang bisa digunakan seperi tehnik relaksasi dan distraksi.

\section{Bagi Tenaga Kesehatan/Program Kesehatan Reproduksi}

Lebih intens lagi untuk melakukan pendekatan kepada remaja dalam hal menangani permasalahan kesehatan reproduksi pada remaja khususnya, sehingga remaja dapat tepat sasaran dalam meminta pertolongan. Pemberian penyuluhan kesehatan tentang reproduksi remaja khususnya permasalahan-permasalahan menstruasi yang terjadi pada remaja dan salah satunya tentang dismenore.

\section{Bagi Peneliti Selanjutnya}

Agar peneliti selanjutnya dapat meneliti variabel-variabel lainnya yang belum diteliti dalam penelitian ini.

\section{Daftar Pustaka}

1. Sukarni, I dan Margareth, Z.H. 2013. Kehamilan, Persalinan dan Nifas, Yogyakarta: Nuha Medika

2. Mulyani, Sri. 2012. Tingkat Pengetahuan Remaja Putri Tentang Disminorea kelas VIII di SMP Negeri 1 Kedawung. Sekolah Tinggi Ilmu Kesehatan Kusuma Husada.

3. Proverawati, A., dan Misaroh, S. 2009. Menarch Menstruasi Pertama Penuh Makna. Yogyakarta

4. Paramita, D.P, 2010. Hubungan Tingkat Pengetahuan Tentang Dismenorea dengan Perilaku Penanganan Dismenorea Pada Siswi SMK YPKK Sleman Yogyakarta.

5. Yuniarti.T,. Rejo dan Handayani.T. 2012. Hubungan Tingkat Pengetahuan Mahasiswa Semester I Tentang Menstruasi dengan Penanganan Dismenore. JK eM-U, Volume IV, No.12, 2012: 18- 25. ISSN: 2085.2754

6. Purba E.P.N, Rompas S, dan Karundeng M. 2014. Hubungan Pengetahuan dengan Perilaku Penanganan Dismenore di SMA Negeri 7 Manado .http://ejournal.unsrat.ac.id

7. Novia, Ika, Puspitasari, Nunik. 2008. Faktor Risiko yang Mempengaruhi Kejadian Dismenore Primer. The Indonesian Journal of Public Health. Vol. 4, No. 2, Maret 2008

8. Releghea A.Y. 2012. Hubungan Antara Pengetahuan Tentang Dismenore Dengan Perilaku Penanganan Dalam Mengatasinya Pada Remaja Putri Di RSBI SMAN Mojoangung. http://repository.unair.ac.id 
9. Nafiroh and Indrawati. 2013. Gambaran Pengetahuan Remaja Tentang Dismenore pada Siswa Putri di MTS NU Mranggen Kabupaten Demak. JIK. 4: 157-66.

10. Notoatmodjo, S. 2012. Metodologi Penelitian Kesehatan. Jakarta: Rineka cipta

11. Bobak, Lowdermilk, Jense. 2012. Buku Ajar Keperawatan Maternitas. Jakarta: EGC

12. Purwani, Herniyatun, Yuniar. 2010. Hubungan Tingkat Pengetahuan Tentang Dismenore Dengan Sikap Penanganan Dismenore Pada Remaja Putri Kelas X Di SMAN I Petanahan. Jurnal Ilmiah Kesehatan Keperawatan. Volume 6 No 1.Februari 2010

13. Kusmiyati, I Wayan Merta, Syamsul Bahri. 2016. Studi Pengetahuan Tentang Menstruasi Dengan Upaya Penanganan Dismenore Pada Mahasiswa Pendidikan Biologi. Jurnal Pijar MIPA. Vol.XI. 1 Maret 2016:47-50

14. Notoatmodjo S. 2012. Promosi Kesehatan dan Perilaku Kesehatan. Jakarta: PT Rineka Cipta.

15. A Potter, \& Perry, A. G. 2007. Buku Ajar Fundamental Keperawatan: Konsep,. Proses, Dan Praktik, edisi 4, Volume.2. Jakarta: EGC

16. Rowen, 2007, Pemijatan, Karisma Publishing Group, Tangerang

17. Oetomo, L. H. (2006). Rahasia Penyembuhan Alami: Cara Sederhana untuk Mengobati Lebih dari 70 Penyakit yang Sering Menyerang Anda. Jakarta: PT. Prestasi Pustakaraya

18. Tamsuri, A. 2006, Konsep dan Penatalaksanaan Nyeri, EGC, Jakarta

19. Asmadi, 2009, Teknik Prosedural Keperawatan: Konsep dan Kebutuhan dasar Klien, Salemba Medika, Jakarta 